\title{
Methods of Valuation of Trees in the Czech Republic
}

\author{
Milan SKALICKY - Vaclav HEJNAK - Jan KUBES \\ Czech University of Life Sciences Prague; Fac. of Agrobiology, Food and Natural Resources, Dept. of Botany \\ and Plant Physiology, Kamycka 129, 16500 Prague, Czech Republic; E-mail: skalicky@af.czu.cz
}

Keywords: chateau garden, hardwood species, shrubs

\section{Introduction}

This thesis deals with the valuation of trees in the chateau gardens in the Czech Republic. The aim of the work was to document tree species, to precisely determine these trees, to determine their basic dendrometric quantities. Furthermore, to determine the additional dendrometric values necessary to evaluate the trees and the subsequent valuation of the individual trees according to the AOPK methodology.

Objectives: It can be assumed that the solitaire trees are more valuable than the trees that are found in groups without management. It can be assumed that a higher value of dendrometric quantities means a higher value of the tree.

\section{Materials and methods}

Documenting and mapping of gardens took place during the growing season. Different literary sources have been used to precisely identify tree species (Grulich, 2012). The nomenclature was unified according to (Danihelka et al., 2012).

The documented tree species were found to be basic dendrological variables: trunk circumference, trunk diameter, tree height, state of health and tree age. Further dendrometric values necessary for tree species evaluation were determined for the selected trees, and subsequently these trees were evaluated using the AOPK Czech Republic software tool. Trees with a trunk circumference of more than $80 \mathrm{~cm}$ were awarded, since in the case of trees with a circumference of over $80 \mathrm{~cm}$ it is necessary to apply for permission to cut the tree. The dendrometric survey was compared with previous surveys.

\section{Results and discussion}

It was found that in the documented area there are 189 trees. Of which 170 pieces of deciduous trees and 19 pieces of conifers. In the garden, 26 species of trees were identified, of which 17 were deciduous trees and 9 coniferous species. The most common species is Tilia cordata. Most of these are linden alleyways. The results of the dossier were compared with the surveys from 2002, 2007 and 2013. The number of trees was found to have decreased. Similarly, the number of species determined has decreased. The tree valuation methodologies, which are used both in the Czech Republic and in the world, were also compared.

\section{Conclusions}

Each tree was precisely determined and its basic quantities were determined. Additional dendrometric values have been determined, necessary for evaluation of trees and subsequent valuation. Research has been compared with surveys in previous years. Based on a comparison with previous surveys, the number of trees was found to have decreased. 


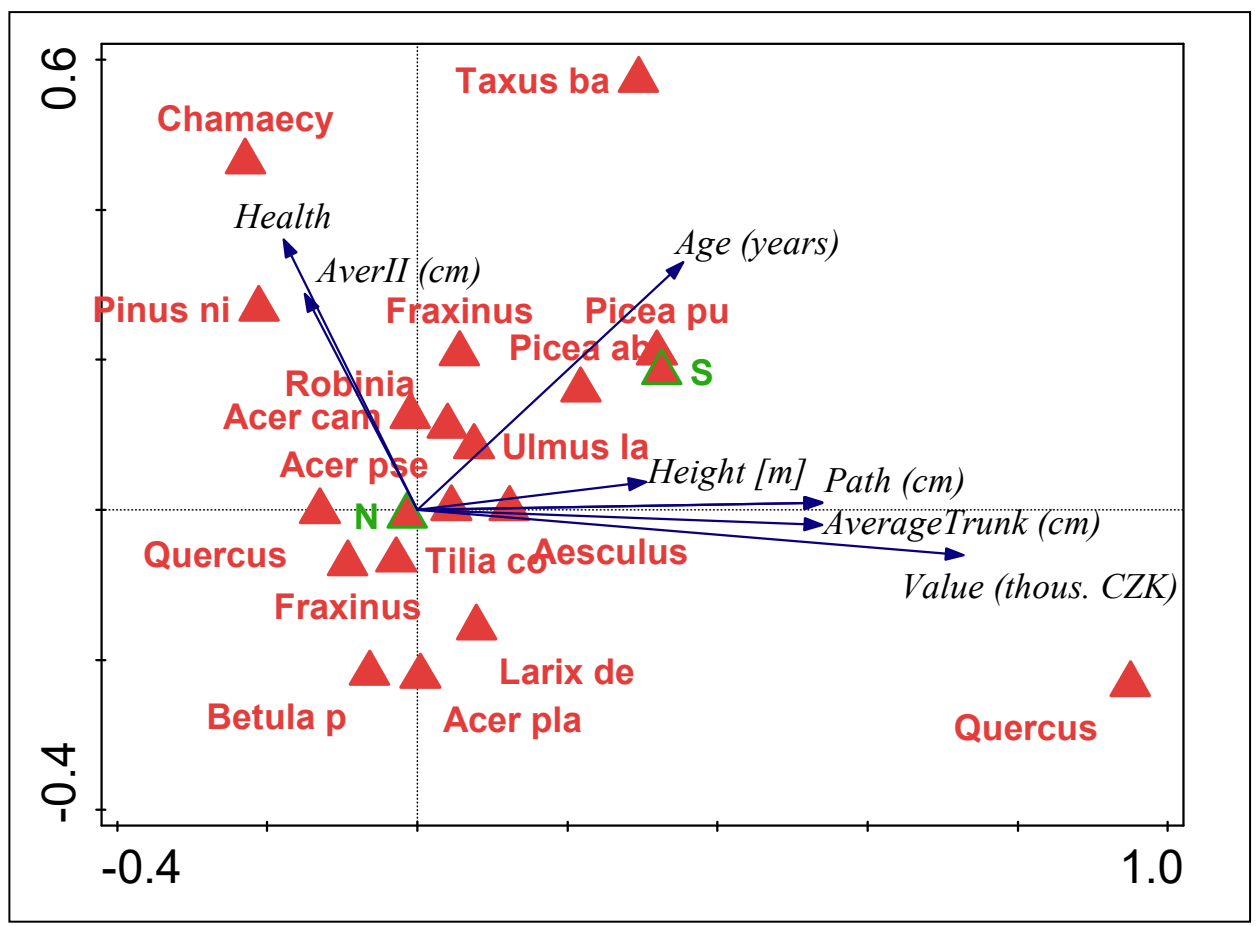

Figure 1: RDA analysis of valuation of trees

Many memorable tree species have been found on documented areas. The individual trees were valued by the methodology of AOPK CZ. Methods of tree valuation have been compared both in the Czech Republic and abroad (USA, Australia, etc.).

\section{Acknowledgement}

Supported by the Ministry of Education, Youth and Sports of the Czech Republic, Project "S grant of MSMT CR".

\section{References}

Danihelka, J., Chrtek, J. Jr., Kaplan, Z. (2012): Checklist of vascular plants of the Czech Republic. Preslia. 84: 3. 647-811.

Grulich, V. (2012): Red List of vascular plants of the Czech Republic: 3rd edition. Preslia. 84: 3. 631-645. 